bulging, or herniation. There was no hair on the right side of the abdomen as there was on the left, and the umbilicus was asymmetrical, being pulled to the left. There was no trouble with the boll in with the bowels; he slept well, ate well, and was very well in general health. But he was unable to read for long, did not like atten'tion for long or maintain a mental effort.

Note by Sir Almroth Wright.

When first examined the pus was found to contain a mixture of the colon bacillus and the Streptococcus faecalis. A vaccine was made from the former and a small dose administered; and at the same time, pending the isolation of the Streptococcus faecalis, a small dose of Streptococcus faecalis which we had in hand was administered.

From the list of blood results it will be seen that the first opsonic index to the streptococcus was 0.28 , and that it kept well up above the normal during the whole course of the treatment, and it was never allowed to go down below the normal. It was clear from the first that the coli infection was subordinate in importance to the streptococcus infection, and from the first blood examination to the coli an opsonic index of 1.12 was obtained. The rest of the coli indices are set down in the second column. Gradually as treatment went on the opsonic index kept high above the normal, and the coli infection became less and less until finally it died away.

The coli inoculations, which had been undertaken alter nately with the streptococcus inoculations, were now abandoned. Soon afterwards the streptococcus inoculations were abandoned, for the streptococcus opsonic index was maintaining itself at a satisfactory height.

\begin{tabular}{|c|c|c|c|}
\hline . & $\begin{array}{c}\text { Date of Blood } \\
\text { Examination. }\end{array}$ & $\begin{array}{l}\text { Opsonic Indices } \\
\text { for Streptococcus } \\
\text { faecalis. }\end{array}$ & $\begin{array}{c}\text { The Colon } \\
\text { Bacillus. }\end{array}$ \\
\hline & December 31st, 1907 & 0.28 & - \\
\hline & January 1st, 1908 & 5.00 & - \\
\hline & " 2nd, , & 1.08 & 1.12 \\
\hline &.,$\quad 3 r d$, & 1.25 & 1.53 \\
\hline & $"$. 4th,, & 1.15 & 1.22 \\
\hline & $" \quad 5$ th,, & 1.07 & 1.15 \\
\hline & $" \quad 6$ th, $"$ & 1.22 & 1.18 \\
\hline & , 7 th, , & 3.44 & 1.16 \\
\hline & $=8 \mathrm{th}, \quad$, & 1.60 & 1.51 \\
\hline & $" \quad 9 \operatorname{th},,$, & 1.17 & 6.16 \\
\hline & "10th, , & 1.56 & 7.00 \\
\hline & " 11th, , & 1.65 & 1.30 \\
\hline & " 13th, ," & 1.87 & 2.07 \\
\hline & " $16 \mathrm{th}, \ldots$ & 2.08 & 1.56 \\
\hline 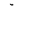 & " 18th, ," & 2.33 & 1,05 \\
\hline & " 21st, ," & 1.52 & 0.55 \\
\hline & , 28th, ," & 1.01 & 1.10 \\
\hline & February 4th, ,, & 1.04 & 1.82 \\
\hline & "12th, ," & - & 1.43 \\
\hline 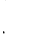 & " 19th, " & 1.24 & - \\
\hline & "29th, " & 1.71 & - \\
\hline
\end{tabular}

In all were administered three injections of coli vaccine amounting to 0 millions, and seven injections of the Streptococcus faecalis amounting to 33 millions.

The Sanitation of Panama.-In a letter acknow ledging the receipt of a report of the Special Commis sion appointed to investigate the state of things on the isthmus of Panama, the President of the United States expresses his satisfaction at all that has been done there. He makes special reference to the success of Colonel Gorgas's sanitary work. "The treatment of hygienic conditions on the isthmus," Mr, Roosevelt writes, "has been such as to make it literally the model for all work of the kind in tropical countries. Five years ago the Isthmus of Panama was a byword for unhealthiness of the : most deadly kind. At present the canal zone is one of the healthiest places on the globe, and the work which is being prosecuted with such tremendous energy is being carried on under conditions so favourable to the health and wellbeing of the worker's that the mortality among them is abnormally small."

\section{AN OPERATION FOR ABSENCE OF THE RECTUM.}

By W. S. McCUNE, M.B., Ch.B.Edin., RESIDENT SURGEON, HORTON INFIRMARY, BANBURY, OXON.

Congenital defects of the rectum and anus, though occurring not infrequently in our large cities, are surgical curiosities in the provinces. As the general practitioner or the surgeon who has never had the opportunity of performing this operation may be called on at any time to interfere, I decided to publish the steps of an operation which proved satisfactory from a surgical standpoint. In Holmes's System of Surgery, vol. iii, 1906, the following remarks with reference to prognosis appear:

The lives of the majority of these patients might have been saved and the patients restored to perfect health had the medical attendant been more familiar with the nature and treatment of the deformity. In some cases life can hardly be preserved; in some it can be preserved ouly at the cost of the infirmity of an artificial anus, but these are the minority.

On March 17th, 1908, a male infant, 27 hours old, was: admitted to the Horton Infirmary. It was full term, well nourished, and weighed $7 \frac{3}{4} \mathrm{lb}$. On examination it was found to have imperforate anus, there having been no attempt at involution of the epiblast. It had passed uncontaminated urine several times, which partly excluded the possibility of the bowel opening into the bladder or urethra. The infant's condition as revealed by operation was, according to Curling's classification (Curling's Diseases of the Rectum, 1876), imperforate anus and partial absence of the rectum, as shown in Fig. 1. As regards the rela-

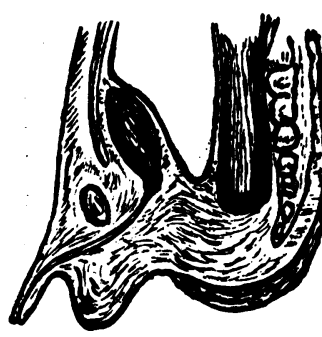

Fig. 1. tive frequency of this condition Curling collected 100 cases of congenital defects of the rectum and anus. Of these, 68 were males.

Shortly after admission the infant was placed on the operating table in the genu-pectoral position, the head being easily rotated to one side for receiving the anaesthetic. Pure chloroform was administered from a small inhaler until reflexes were abolished. An incision $1 \frac{1}{2}$ in long was made, starting from just behind the central point of the perineum, extending backwards almost to the tip of the coccyx. A careful dissection was then begun. As it was almost impossible to recognise any of the "land. marks" in this region when the tissues became bathed in blood, and as the size of the wound restricted necessary manipulation, the incision was carried backward for another 1 in. Retractors were inserted laterally; the surgeon continued his dissection, using as his only guide an axis which would have corresponded with the normal rectum had it been present; this axis-the infant being in the genupectoral position-being inwards, upwards, and backwards, as shown in Fig. 2. Working along this line brought the operator to the blind end of the bowel. The depth of the wound at this stage of the operation was about $1 \frac{3}{4}$ in. The blind end of the bowel was identified by the resonant " ring" which was produced by scraping the tissues in the region with the point of a scalpel. To verify this sign, the chloroform was withdrawn for a little and the child allowed to strain.

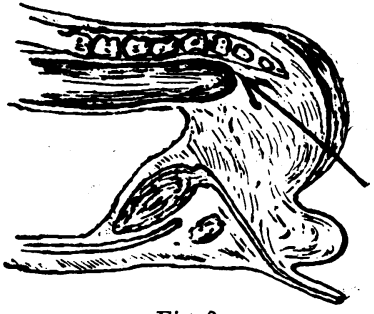

Fig. 2,
At the same time the abdomen was pressed firmly with the hand. These two factors were very efficient in rendering the object of search apparent. The areolar tissue surrounding the end of the bowel was seized with a pair of Liston's artery forceps and gentle traction applied. Some surgeons advocate light anaesthesia during these operations, but the operator in this case preferred the infant to be well " under." The spasmodic contractions of the peronei and levatores ani muscles impeded his progress. 
He also wished to avoid any sudden straining or movement of the infant causing him to puncture the bowel. Still keeping up gentle traction, the tissues surrounding the bowel were carefully dissected away until about an inch of it had been isolated. The bowel could now be pulled down to the edges of the wound. This was done and a suture inserted on each side, fixing it in position. An incision was now made in the bowel corresponding in extent to its antero-posterior diameter. A considerable 'volume of flatus escaped, followed by meconium. This completely relaxed the bowel, preventing the sutures from exercising tension. The edges of the bowel incision were scraped -firmly with the edge of a scalpel in order to enhance the security of subsequent adhesions. Four fine sutures were inserted, fixing the bowel to the edges of the wound; these sutures included the skin, superticial and deep fasciae. The operation wound was sutured anteriorly and posteriorly with deep sutures. Five inches of No. 22 drainage tubing was then inserted for $2 \mathrm{in}$. into the rectum. The protruding 3 in. was split, everted, and kept in that position by overlapping the two halves with dressings. The opera tion occupied 1 hour 5 min., during $50 \mathrm{~min}$. of which the child was well " under."

Its immediate recovery was good. It was not sick on the table. An hour afterwards it vomited about 2 oz. dark yellow fluid. Subsequently it was fed from the bottle, taking its nourishment greedily. For a few days the contents of the bowel flowed out unrestrained. In six days cicatrization had advanced far enough to allow of some degree of control of the artificial anus, its circum ference being considerably less than that of the bowel immediately above. The edges had gained firm adhesions to the lips of the wound and the underlying tissues. The tube was taken out morning and evening for 8 days; at the same time the bowel was irrigated gently. On removing the tube on the morning of the eighth day the anus could be seen firmly contracting. The tip of the little finger was prevented entrance by the very effective sphincter action which was present. The perineal, levatores ani, and circular muscle fibres of the bowel had apparently compensated for the absent sphincters. From this time until the infant died, which was thirty-seven days after the operation, the bowels were evacuated twice a day. On this point the following occurs in Holmes's System of Surgery, vol. iii, 1906 :

Even where the gut has not been drawn down to the skin the power of controlling the faeces may be hoped for. A sphincter muscle has been proved to exist in a case of this kind, but if the gut have been attached to skin its circular fibres wil assume the office of a sphincter even when no external sphincter exists.

Three weeks after the operation the infant became jaundiced; this passed off to a great extent in a few days, but the sclerotics remained tinted until death. As an -autopsy was not permitted, to certify the exact cause of death was difficult. The infant lived over five weeks, during which time no complication as the result. of operation presented itself. Its systems were normal. The anaesthesia for operation was deep and protracted for a child of tender age, 4.4 drachms being the amount of chloroform necessary to maintain the depth of anaesthesia required. From this point of view, delayed or chronic chloroform poisoning may have been a factor in bringing about the death. Drs. McDonald and Stiles (S.M. and S.J., August 1904) have shown the toxic effect of repeated or protracted chloroform inhalation. The infant in consideration apparently lived too long to have died from this cause, but the injury to the vital tissues of the body at time of inhalation may have paved the way for organic disease.

I have to thank Dr. Johns, Honorary Surgeon to the Horton Infirmary, for permission to publish the report of this case.

BIBLIOGRAPHY.

Esmarch, Die Krankheiten des Mastdarmes und des Afters. Le Dentu, Traite de Chirurgie, vol. viii. Holmes, System of Surgery, Edition 3, vol. iii. Holmes, Diseases of the Rectum, 1876. Treatise on the Pathology and Treatment of Congenital Malformations of the of the Rectum and Anus, and a similar work by Goodsall and Miles.

THE Sanitary Inspectors' Association, which was in conference at Liverpool last week, adopted unanimously a resolution declaring that meat inspection in this country could never be carried out efficiently until all private slaughterhouses had been abolished.

\section{PERFORATED GASTRIC ULCER: OPERATION 44 HOURS AFTER PERFORATION : RECOVERY.}

BY ARTHUR C. ROPER, F.R.C.S.ED.,

SURGEON TO THE ROYAL DEVON AND EXETER HOSPITAL.

For the notes of the following case I am entirely indebted to our House-Surgeon, Mr. Harmer, to whose constant and assiduous care, together with the excellent nursing she received, the patient chiefly owes her recovery.

\section{History}

Alice B., aged 21, a kitchen maid, married, had suffered from pain in the stomach after food for many months, and during that time had lived almost entirely on a liquid diet. There was no history of haematemesis.

On November 6th, 1907, she took a light supper at 8.30 p.m. consisting of chicken, bread, etc., and soon after went to bed, and to sleep. She awoke at about $10 \mathrm{p.m}$. with violent pain in the abdomen, not localized, but most acute round the umbilicus, shooting through to the back. Brandy was given and caused immediate vomiting. Pain continued throughout the night, and she vomited again after more brandy during the night. At about 7 a.m. she was seen by a medical man, who found her about 7 a.m. she was seen by a medical man, who found her suffering from violent aludominal pain, quite unable to give any account of herself, and in such a state of collapse that he did not venture to remove her to hospital at that time. He diagnosed perforated appendix, ordered a sedative mixture of bismuth, etc., and a milk diet. Towards the afternoon the pain abated,
and she had a fairly comfortable night with no further sickness. On the afternoon of November 8 th her doctor sent her to the hospital.

Condition on Admission.

The face was pale and pinched, but the lips were of a good red colour. The eyes had the typical restless appearance of general peritonitis. She appeared to be suffering no pain, and only complained of great thirst. She was apathetic and did not realize that she was seriously ill. The tongue was covered with thick creamy fur. The pulse was 130, regular, dicrotic themperare 101.8 .

There was general distension of the abdomen, which did not move in respiration; there was resistance to palpation all move in respiration; there was resistance to palpation all Tenderness was present all over the abdomen, but was most marked in the epigastric and right iliac regions, but even here marked in the epigastric and right iliac regions, but even here only subacute. There were patches of dullness in places, chiefly between the umbilicus and the epigastric notch. There was no dullness in the flanks, and the liver dullness was normal. Mr.
Roper saw the case 43 hours after the onset of the attack, diagnosed perforation of the stomach, and decided to operate.

\section{Operation.}

At 6 p.m. an incision was made slightly to the left of the At 6 p.m. an incision was made slightly to the left of the middle line. The peritoneum was like raw ham, $\frac{1}{4}$ milk was and fleshy. On opening it about a pint of curdled milk was scooped away; it was contained in a cavity surrounded by dense adhesions below and at the sides, but running up to the Milky contents of the stomach were wiped away until it was possible, by lifting the left lower ribs, to see the perforation high up on the lesser curvature and near the cardiac end of the stomach The opening was circular and about $\frac{1}{3}$ in. in diameter ; the stomach was oedematous and tense from surrounding adhesions. An attempt was made to close the aperture with silk sutures, but the site being almost inaccessible, great difficulty was experienced in inserting the sutures, and, great difficulty was experienced in inserting the sutures, and when tied, they cut through the friable

A second incision was made in the right iliac region, and the adhesions which shut off the flanks were broken down by hand. The pelvis was found to be full of milky fluid. All the The pelvis was found to be full of milky "wuid. All the bowels exposed were coated with yellow "wash leather" lymph adherent to each other. The adhesions over the front of pass a rubber tube across and flush out the left iliac fossa. The abdomen was then flushed with hot normal saline from each kidney pouch until it ran clear from the lower opening. A rubber tube was put through the lower opening into Douglas's pouch, and a wick drain down to the perforation in the stomach and the upper part of the incision closed by suture. The operation lasted 55 minutes and the patient suffered comparatively little shock. The pulse at the end was 140, regular, less forcible and more dicrotic.

After-History.

A suppository of opium or $j$ was introduced and a hypoA suppository of opuchnine gr. dermic injection of strychnine gr. ks and digitalin gr. 1 10 given every four hours, a nutrient suppository every

enema of normal saline 3 x every six hours. At 10 p.m. it was noted that she had twice vomited small quantities of green clear fluid, the apathetic condition continued, she had no pain, no discomfort, and only complained of intense thirst. The pulse was 136, and the temperature $99^{\circ}$. She began to have abdominal pain in the early morning, but when examined the pulse was found to be much better, 110, full, 